This is a postprint of the Journal of Pharmaceutical Sciences, Volume 101, October 2012, Pages 3687-3697.

The original article can be found under http://onlinelibrary.wiley.com/doi/10.1002/jps.23227/full

\title{
Rational coformer or solvent selection for pharmaceutical co-crystallization or desolvation
}

Yuriy A. Abramov ${ }^{\mathrm{a}, *}$, Christoph Loschen ${ }^{\mathrm{b},{ }^{, *}}$, Andreas Klamt ${ }^{\mathrm{b}, \mathrm{c}}$

${ }^{a}$ Pfizer Global Research and Development, Groton, Conneticut, United States

${ }^{\mathrm{b}} \mathrm{COSMO}$ logic GmbH \& Co. KG, Burscheider Str. 515, 51381 Leverkusen, Germany

${ }^{c}$ Institute of Physical and Theoretical Chemistry, University of Regensburg, Regensburg,

Germany

* corresponding author: E-mail: yuriy.a.abramov@ pfizer.com. Tel.: +1-860-908-2303.

**corresponding author: E-mail: loschen@ cosmologic.de. Tel.: +49-2171-363667. 
ABSTRACT: It is demonstrated that the fluid phase thermodynamics theory COSMO-RS as implemented in the COSMOtherm software can be used for accurate and efficient screening of coformers for API co-crystallization. The excess enthalpy, $\mathrm{H}_{\mathrm{ex}}$, between an API-coformer mixture relative to the pure components reflects the tendency of those two compounds to cocrystallize. Thus, predictive calculations may be performed with decent effort on a large set of molecular data in order to identify potentially new co-crystal systems. In addition it is demonstrated that COSMO-RS theory allows reasonable ranking of coformers for API solubility improvement. As a result, experiments may be focused on those coformers which have an increased probability of co-crystallization leading to the largest improvement of the API solubility.

In a similar way as potential coformers are identified for co-crystallization, solvents which do not tend to form solvates may be determined based on the highest excess enthalpies with the API. The approach was successfully tested on tyrosine kinase inhibitor axitinib which has a propensity to form relatively stable solvated structures with the majority of common solvents, as well as on thiophanate-methyl and thiophanate-ethyl benzimidazole fungicides, which form channel solvates.

KEYWORDS: cocrystals; solvates; desolvation; crystallization; in silico modeling; crystal engineering; solubility; COSMO-RS; excess enthalpy 


\section{INTRODUCTION}

Co-crystals can be defined as homogeneous solid phases containing two or more neutral compounds in a crystal lattice with defined stoichiometry, which are solids in their pure form at ambient conditions. ${ }^{1}$ The transformation of active pharmaceutical ingredients (APIs) from their pure crystalline form into co-crystals has experienced increasing interest recently. A co-crystal of the API and an additional compound may show modified properties (such as solubility, dissolution rate, physical and chemical stability) as compared to the pure compounds. ${ }^{2,3}$ The possibility to improve the bioavailability ${ }^{4,5}$ of the API and to create patentable intellectual property $^{6,7}$ constitutes a new and highly attractive route for drug development.

Various experimental methodologies are currently employed for co-crystallization including grinding ${ }^{8,9}$ crystallization from melt, ${ }^{10}$ traditional solution crystallization approaches, such as solvent evaporation, ${ }^{11}$ cooling or antisolvent addition, and slurry crystallization. ${ }^{12}$ These experimental techniques are typically time-consuming and expensive. Therefore the ability to predict the propensity of different coformers to form a co-crystal with the given API is important.

From general consideration a likelihood of co-crystal formation is related to the miscibility of API and coformer in the solid state. For a crystalline material miscibility should be defined by the co-crystal lattice energy. In fact, it was demonstrated previously that rationalization of cocrystal formation in certain cases may be achieved by crystal structure prediction 
techniques. ${ }^{13,14,15,16}$ However these methods are time consuming and cannot be applied for virtual coformer screening. The effectiveness of the current crystal structure prediction methods quickly decreases with an increase in system complexity (number of molecules in the asymmetric unit and their conformational flexibility). Therefore the majority of the current computational approaches to virtual coformer screening neglect stabilizing long-order packing contributions to the coformers miscibility.

In practice rationalization of co-crystal formation is typically based on consideration of only dominant contributions to the miscibility. Intermolecular hydrogen bonding interaction is the most common focus due to its high strength and directionality. For example, the rational design of co-crystallization is typically performed by a crystal engineering approach which is based on a hierarchy of hydrogen-bonded supramolecular synthons. ${ }^{17,18,19}$ A theoretical model was recently proposed for virtual screening based on hydrogen bonding propensities of co-crystal formers derived from molecular electrostatic potential surfaces calculations. ${ }^{20}$ Alternatively statistical analysis of Cambridge Structural Database $(\mathrm{CSD})^{21}$ was performed and a model of molecular complementary in co-crystals was suggested for virtual coformer screening, which was based predominantly on shape and polarity of co-crystal formers. ${ }^{22}$ Hydrogen bond donor and acceptor counts showed no obvious statistical relationship. A potential drawback of the model is that it was trained on co-crystal observations in the CSD database ignoring potential failures in realistic co-crystal screenings. Babu et al. have calculated H-bond energies of amide and N-oxide synthons at the HF/6-31G* level in order to compute cocrystal formation. ${ }^{23}$ In addition, Hansen solubility parameters were recently applied to describe miscibility of API and coformer to predict co-crystal formation to guide co-crystal screening. ${ }^{24}$ 
In the current study we demonstrate how COSMO- $\mathrm{RS}^{25}$ fluid phase thermodynamics computations describing miscibility of co-crystal formers in a super-cooled liquid (melt) phase can be applied to virtual coformer screening. It is assumed that the supercooled liquid phase mimics the co-crystal solid state neglecting long order packing contributions (an amorphous solid state). An extensive testing of the approach on multiple experimental screening observations, including pharmaceutical APIs paracetamol, bicalutamide, itraconazole, nicotinamide, meloxicam, carbamazepine and indomethacine is reported. Concerning the predictivity of the approach, it should be taken into account that a negative experimental result of co-crystallization of an API with a coformer does not completely exclude the possibility that such co-crystal exists. There are many reasons why it just may not have been observed in the specific experimental setup.

In a similar way as potential coformers are identified, solvents which do not tend to form solid solvates (sometimes called pseudopolymorphs) with the API may be found by COSMO-RS fluid phase thermodynamics computations. The main difference between solvates and cocrystals is the physical state of the isolated pure components: if one component is a liquid at room temperature, the crystals are designated as solvates. While co-crystal formulation can bring advantages by increasing dissolution rate and bioavailability of the API, solvate formation is typically undesirable. Solvates might be subsequently desolvated in a final drying step of formulation process. In such a situation the final polymorph could be metastable and undergo solid-solid transition during its shelf-life. In addition, residual solvent levels in the API must be compatible with ICH guidelines (http://www.ich.org) in case of incomplete desolvation. 
Therefore selection of the solvent system for crystallization which has the lowest probability of forming solvates with the API is important. Such solvent systems in general may be used directly for slurry crystallization of the stable form or for desolvation of the solvated forms by reslurry experiments to facilitate solvent-mediated transformation and conversion to a stable anhydrous non-solvated form.

In the current study we demonstrated how fluid phase thermodynamics calculations allow selecting solvents which do not form solvates with a tyrosine kinase inhibitor axitinib (trade name Inlyta), and with fungicides thiophanate-methyl and thiophanate-ethyl.

Previously such an idea was suggested ${ }^{26}$ but never attempted for the solvent selection using the Fábián model. ${ }^{22}$

\section{APPROACH AND METHODS}

\section{Approach}

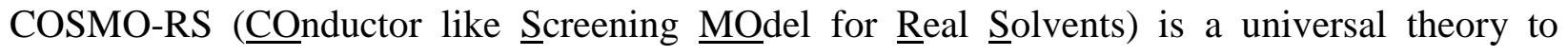
predict the thermodynamic equilibrium properties of liquids, which was originally developed by A. Klamt. ${ }^{25,27}$ COSMO-RS thermodynamics is based on the statistical physics of interacting molecular surface segments. The polar and hydrogen bond interaction energies are quantified based on the surface screening charge densities, which result from a quantum chemical continuum solvation calculation. Due to its ability to treat mixtures at variable temperatures and to compute accurate solvation energies based on first-principles, it has become very useful in chemical engineering and in wide areas of physical and medicinal chemistry. 
A complete computational modeling and prediction of the co-crystallization process is currently out of reach due to the complexity of the involved steps like nucleation and crystal growth. However, with COSMO-RS being a fluid phase thermodynamics model, it is possible to compute a virtually supercooled liquid mixture of the co-crystallization components and obtain the excess enthalpy of stoichiometric m:n mixtures created out of the pure components A and B:

$$
H_{e x}=H_{A B}-x_{m} H_{p u r e, A}-x_{n} H_{p u r e, B}
$$

$\mathrm{H}_{\text {pure }}$ and $\mathrm{H}_{\mathrm{AB}}$ represent the molar enthalpies in the pure reference state and in the m:n mixture, with mole fractions $x_{m}=m /(m+n)$ and $x_{n}=n /(m+n) . H_{e x}$ contains all enthalpic contributions and is not limited to hydrogen bonding interactions, though those may be separated from the overall enthalpy by COSMOtherm software. ${ }^{28}$ We found that the excess enthalpy $\mathrm{H}_{\mathrm{ex}}$ is a superior descriptor to the pure hydrogen bonding interaction. Compounds with $\mathrm{H}_{\mathrm{ex}}<0$ are strongly attractively interacting in solution (super-cooled liquid) and prefer the mixture enthalpically over their pure liquids. In an extensive set of test calculations presented below we demonstrated that coformers miscibility as measured by $\mathrm{H}_{\mathrm{ex}}$ corresponds nicely with an increased probability of forming co-crystals. Since it is reasonable to assume, that enthalpic preference of such supercooled liquid phase will also pertain in a mixed crystal, it is plausible to use the liquid phase excess enthalpy as a guide for co-crystal screening.

\section{Methods}

Excess enthalpies, $\mathrm{H}_{\mathrm{ex}}$, were calculated by the COSMOtherm software. ${ }^{28}$ The screening charge densities for COSMOtherm calculations were generated by the Turbomole package ${ }^{29}$, using the BP86 density functional ${ }^{30,31}$ with a TZVP ${ }^{32}$ basis set (BP-TZVP-COSMO level of theory). The

COSMOfrag 3.3 module ${ }^{33}$ was adopted for increased screening performance of large dataset of 
coformers. Multiple conformations of APIs and coformers were generated by COSMOconf $2.1^{34}$ or OMEGA ${ }^{35}$ (YAA) softwares and adopted for the $\mathrm{H}_{\mathrm{ex}}$ calculations.

\section{RESULTS AND DISCUSSION}

\section{Rational Coformer Selection for Co-crystallization}

\section{Test of the Approach}

For an extensive testing experimental results of co-crystal screening for multiple APIs were taken from literature sources. ${ }^{19,20,24,36,37,39,40,41,42}$ Results of virtual coformer selections are compared with the experimental observations in Tables 1 and 2 for the selected cases (see Supplementary materials for all other cases considered in this study).

Overall performance of the COSMO-RS model for coformer selection was estimated by ROC (Receiver Operator Characteristic) curves (Figure 1). A ROC curve plots the sensitivity (number of true positive predictions/total number of positive observations) vs. 1-specificity (number of false positive predictions/total number of negative observations), for a binary classifier system (co-crystal screening results) as its discrimination threshold $\left(\mathrm{H}_{\mathrm{ex}}\right.$ cut-off) is varied from small to higher values. The area under the curve (AUC) measures the overall performance of the model. Predictions with higher AUCs are generally better and should always be higher than 0.5 , indicating the model is better than random selection.

Sometimes the goal of solid crystalline formulation is to find at least one co-crystal former. That is why in addition to the ROC curves, which measure the overall performance of the model, we used enrichment factor $(\mathrm{EF})$ criteria, which measures the probability of getting the 
first hit (co-crystal) based on $\mathrm{H}_{\mathrm{ex}}$ ranking relative to the random selection. $\mathrm{EF}$ in this case is defined as: $E F=\left(1 / N_{f h}\right) /\left(n_{h} / N\right)$. Here $N_{f h}$ is the number of coformers screened to get the first hit; $\mathrm{n}_{\mathrm{h}}$ - total number of hits (coformers forming co-crystal(s)) in the screening set); $\mathrm{N}-$ total number of coformers in the screening set. The maximum enrichment factor, $\mathrm{EF}_{\max }\left(\mathrm{N}_{\mathrm{fh}}=1\right)$, is equal to $\mathrm{N} / \mathrm{n}_{\mathrm{h}}$.

As an example we present here details of a rational coformer selection for itracanozole cocrystallization. Results of crystal engineering of co-crystals of antifungal drug itracanozole with 1,4-dicarboxylic acids were recently reported. ${ }^{36}$ The co-crystals dissolution behavior was shown to be more similar to commercial Sporanox beads (amorphous) than to micronized crystalline itraconazole. The COSMO-RS selection of the coformers based on the excess enthalpies displayed an excellent performance (Table 1). All experimentally observed co-crystals are ranked at the top of the list with no false negative outliers. The enrichment factor displayed the maximum value of 2 . Please note also that even the difference towards co-crystal formation between the trans- and cis-isomers (see discussion in the next section), fumaric and maleic acid, respectively are predicted correctly at the BP-TZVP-COSMO parameterization.

The performance of coformer screening based on the excess enthalpy as computed with the COSMOtherm program at the BP-TZVP-COSMO level is presented by ROC curves for all the test cases considered in the current study in Fig.1. The corresponding AUC and EF values are summarized in Table 2.

The overall performance of the proposed model is quite good. In seven out of twelve virtual coformer screenings the AUC was equal or higher than 0.7. Enrichment factors for eight 
coformer selections displayed the maximum values, $\mathrm{EF}_{\max }$. A poor performance was observed for reproduction of indomethacin experimental screening observations. That probably can be accounted for by relatively strong contributions of lattice packing effects in the indomethacin cocrystals, which are ignored by the COSMO-RS calculations. Furthermore, most of the co-crystals observed in reference 37 were obtained by transformation from the solvate with dioxane $\left(\mathrm{H}_{\mathrm{ex}}=-\right.$ $1.3 \mathrm{kcal} / \mathrm{mol})$. It cannot be completely ruled out that using a different, less strongly bound solvent would yield additional co-crystals.

\section{Exploring Limitations of the Approach}

The proposed method is based on the miscibility of co-crystal formers in a super-cooled liquid phase as measured by $\mathrm{H}_{\mathrm{ex}}$, ignoring the crystal packing effects. Therefore optimal screening of coformers should be expected in case differences in $\mathrm{H}_{\mathrm{ex}}$ contributions exceed variations due to the packing effects.

The above considerations suggest that prediction of differences in the cocrystal forming ability between isomeric compounds may be a challenging task. The surface screening charge densities of isomers are typically almost identical leading to very close $\mathrm{H}_{\mathrm{ex}}$ values with a given cocrystal former. If in such a case the packing in the cocrystalline phases is energetically very different, as it may be the case for isomers having differently directed H-bonding groups, resulting in a different $\mathrm{H}$-bonding pattern, a prediction solely based on the mixing behavior will fail.

An illustration of such a case is the cocrystallization screening of isonicotinamide and 
nicotinamide with 4-hydroxybenzoic acid, clofibric acid and diclofenac (Table 3) based on a experimental study recently carried out by Báthori et al. ${ }^{38}$ It can be seen that the method is getting an ideal enrichment of coformer selection for nicotinamide cocrystallization. However, the obtained $\mathrm{H}_{\mathrm{ex}}$ results fail to provide any insights into experimentally observed difference in cocrystal forming ability between nicotinamide and isonicotinamide.

\section{Coformer Ranking for Solubility Improvement}

Apart from coformer screening for co-crystallization, the COSMOtherm software suite may be applied to coformer ranking for co-crystal solubility improvement. The underlying equations for such calculations were presented previously and are summarized below.

In case of neutral API and acidic coformer a co-crystal solubility at a given $\mathrm{pH}$ may be

calculated according to the following equations (see Supplementary material): ${ }^{43,44}$

$$
\log \left(S_{A m B n}\right)=\frac{1}{n+m}\left[\log K_{s p}-m \log (m)-n \log (n)+\log \left(1+10^{p H-p K a}\right)\right]
$$

where

$$
\log K_{s p}=-\frac{1}{\ln (10) R T}\left[m \mu_{\text {solvent }}^{*_{A}}+n \mu_{\text {solvent }}^{*_{B}}-m \mu_{\text {liquid }}^{*_{A}}-m R T \ln \frac{m}{n+m}-n \mu_{\text {liquid }}^{*_{B}}-n R T \ln \frac{n}{n+m}+\Delta G_{\text {fus. }}\right] \text {. }
$$

Here $S_{A m B n}$ is a solubility of $A_{m} B_{n}$ co-crystal, defined by a mass balance as $A_{m} B_{n}=[A] / m=$ $[\mathrm{B}] / \mathrm{n} ; \Delta \mathrm{G}_{\mathrm{fus}}$ is the free energy of fusion of the co-crystal; $\mathrm{pK}_{\mathrm{a}}$ is the dissociation constant of an acidic coformer $\mathrm{B} ; \mu^{*}$ is a pseudo-chemical potential of the co-crystal components in solvent (water) or in the pure supercooled liquid state as defined by Ben-Naim. ${ }^{45}$ These pseudo-chemical potentials are evaluated with the COSMOtherm software. Typically the co-crystal free energy of 
fusion is unknown and currently cannot be predicted. Therefore for the solubility ranking we neglected this contribution, assuming $\Delta \mathrm{G}_{\text {fus }}=0$.

In Figure 3 the predicted solubility ranking of carbamazepine cocrystals in water is compared with experimental observations. ${ }^{43}$ There is a reasonable agreement with experimental data which would allow, for example, selecting nicotinamide coformer for the largest solubility improvement of the drug. The slope between experimental observations and predictions is close to unity within the estimated standard deviation.

\section{High Throughput Computational Co-crystal-Screening from Molecular Libraries}

The computation of excess enthalpies can be done comparatively easy for a large set of compounds in order to identify possibly new API-coformer pairs. In the following we test such a screening approach for the well-investigated drugs paracetamol and meloxicam by mingling a set of experimentally known coformers with a large list of FDA approved compounds from a

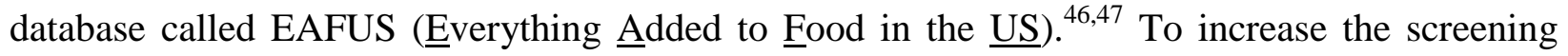
performance we used the COSMOfrag module, which allows for the rapid generation of an approximate $\sigma$-profile for the molecules just starting from a SMILES string based on comparison with a database of already existing $\sigma$-profiles. ${ }^{33}$ In other words, this approach allows generating instantaneously data of nearly quantum chemical accuracy without performing any such explicit and costly calculation. Thus, a screening is done for several hundred compounds within minutes. Figure 3 shows an enrichment plot (rocking plot) for both drugs which have been screened against this list including known coformers of paracetamol ${ }^{42,48,49,50,51}$ and meloxicam..$^{40,52,53}$ The plot has been generated just by ordering the results according to the excess enthalpy $\mathrm{H}_{\mathrm{ex}}$ of each API conformer pair. 
For both drugs we find nearly all to our best knowledge known coformers within the first third of the screened list. The only exception is the paracetamol coformer naphthalene whichshows up very late, after about 90\%; indeed it is quite surprising that such an unpolar compound forms a co-crystal with paracetamol anyway. Its enthalpic interaction with this drug is rather small and therefore this is a case where crystallization is dominated by efficient packing. Concerning meloxicam the screening obtained sulfuric acid as the compound with the lowest excess enthalpy. Although sulfuric acid itself is not known so far to co-crystallize with this API, interestingly, a literature research revealed that meloxicam hydrogen sulphate is known as a salt. $^{54}$ There is also a somewhat extended plateau in Figure 2, at about $2 \%$ to $5 \%$ of the sampled compounds, which is mainly due to all kind of different nitrogen heterocyclic compounds like pyridines, pyrazines and oxazoles. A negative excess enthalpy of meloxicam with those compounds is caused by the interactions of the meloxicam alcohol group with the aromatic nitrogen according to the contact statistics of the COSMOtherm calculations. Those compounds could be interesting targets as alternatives to the acidic compounds used so far in experimental trials.

Of course such a coarse screening will have to be refined by manual selection of the most promising systems by an experienced crystal engineer, but anyway we believe that this is a promising approach to enrich the standard conformer portfolio of drug developers with novel and perhaps unexpected compounds.

\section{Application to Solvent Selection to Avoid Solvate Crystallization}

\section{Axitinib}

Axitinib is a small molecule tyrosine kinase inhibitor developed by Pfizer (Figure 4 a). This active pharmaceutical ingredient targets the vascular endothelial growth factor (VEGF) to 
prevent the growth and proliferation of cancer cells via interruption of tumor angiogenesis (formation of vascular supply tissue). Axitinib has shown to be a polymorphically complex API, with 5 anhydrous forms and 66 solvated forms known. ${ }^{55,56}$

Axitinib has a propensity to form relatively stable solvated structures, as a majority of these solvates were characterized as possessing relatively high temperatures of desolvation (desolvation temperatures significantly higher than the normal boiling point of the corresponding solvent), suggesting strong bonding within the crystal. ${ }^{55,26}$ These solvates are thermodynamically stable in their corresponding mother liquor and may resist further solvent-mediated transformation to an anhydrous form. From crystallographic consideration depending on molecular size and hydrogen-bonding features, the solvent can either occupy pockets between axitinib dimers forming pocket solvates or link these dimers together by hydrogen bonding with the pyridine or the pyrazole acceptor and the amide donor. ${ }^{56}$ Majority of solvates displaying higher desolvation temperatures than the boiling point appeared to be pocket solvates. ${ }^{56,26}$

The excess enthalpy calculations were performed for 1:1 liquid mixtures of axitinib with 46 pure solvents, described by Campeta et al (Table 4). ${ }^{55}$ Slurry crystallization in all of these solvents except for heptane resulted in solvate formation. ${ }^{55}$ Positive $\mathrm{H}_{\mathrm{ex}}$ values were predicted for 24 solvents, 23 of which form solid solvates with axitinib. That indicates that low miscibility of axitinib with these 23 solvents in the supercooled liquid phase is counterbalanced by lattice packing (3D order) contributions in the solid state, which are ignored in the current calculations. Nevertheless as in the case of coformer selection for co-crystallization we assume that 
miscibility in supercooled liquid as measured by $\mathrm{H}_{\mathrm{ex}}$ can be sufficient for ranking solvents propensity to form solid solvates.

Heptane was found to have the highest excess enthalpy value among all considered solvents (Table 4). That corresponds to the lowest miscibility with axitinib in the supercooled liquid mixture. Heptane indeed was one of the few solvents that did not solvate with axitinib and would be expected to be partially miscible with most solvents at high temperature to facilitate desolvation. In fact heptane was adopted for solvent-mediated desolvation experiments through solvates reslurry at $105^{\circ} \mathrm{C}^{55}$ The resulting enrichment factor provided by $\mathrm{H}_{\mathrm{ex}}$ ranking is 46 .

\section{Thiophanate-methyl and Thiophanate-ethyl}

Polymorph and solvate formation studies were recently reported for two fungicidal compounds: thiophanate-methyl, TM (dimethyl 4,4'-(o-phenylene)bis(3-thioallophanate) and thiophanateethyl, TE (diethyl 4,4'-(o-phenylene)bis(3-thioallophanate) (Figure $4 \mathrm{~b}$ and c). ${ }^{57,58}$ Though the two molecules are close analogues and differ only by two $\mathrm{CH}_{2}$ groups they display varying combination of hydrogen bonding arrangment and molecular conformations in solid state.

Both molecules willingly form polymorphs and solvates: TM has two conformational polymorphs and at least fourteen solvates, ${ }^{57,58}$ while four polymorphs and seven solvates were reported for TE. ${ }^{58}$ The solvent molecules occupy channels running through the crystal structures, displaying hydrogen bonding and/or van der Waals interactions with the host molecules. Due to the additional $\mathrm{CH}_{2}$ groups TE molecules allow formation of larger channels than those observed in the crystal structures of the TM solvates. As a result majority of the 
studied solvents do not engage in hydrogen bonding with the TE molecules in contrast to predominance of the hydrogen bonded TM solvates.

Due to a higher mobility of the solvent molecule and the presence of geometric constraintsimposedby the cavity size, channel solvate formation seems to be a challenging test to the application based on the excess enthalpy calculations only.

Virtual solvent screening results based on the $\mathrm{H}_{\mathrm{ex}}$ calculations for liquid mixtures of TM and TE with pure solvents are presented Tables 4 and 5, respectively. Water was found to have the highest excess enthalpy value among all considered solvents, supporting lack of the experimental observation of TM and TE pure hydrates. Toluene solvent was correctly ranked as the second top solvent, which does not form solvates with TM (Tabe 5). Methanol, ethanol and 1,2-DCE solvents which do not form TE solvates are ranked at the top of the solvent list with toluene as a false positive prediction (Table 6). Strong false negative predictions were given to DMA and DMSO solvents for which TM and TE solvates, respectively, were not observed.

In spite of the complexity of the test, a reasonably good overall performance of the proposed method in application to TM and TE channel solvates is reflected in the maximum enrichment factors of 17 and 12 and AUC values of 0.63 and 0.67 , respectively.

\section{CONCLUSIONS}

It is demonstrated that COSMO-RS theory as implemented in the COSMOtherm software offers a highly efficient way to preselect co-crystal coformers by computational screening. This is 
achieved by the calculation of the excess enthalpy $\mathrm{H}_{\mathrm{ex}}$ which may be interpreted as the tendency of the two components to associate in the mixture prior to co-crystallization. Most likely due to its detailed and accurate description of all intermolecular interactions, COSMOtherm appears to be more accurate in coformer ranking than some other specially developed procedures, which are focused on intermolecular hydrogen bonding. In addition it is demonstrated that COSMOtherm allows reasonable ranking of coformers for API solubility improvement. As a result, experiments may be focused on those coformers which have an increased probability of co-crystallization leading to the largest improvement of the API solubility.

In a similar way as potential coformers are identified for co-crystallization, solvents which have the lowest probability to form solid solvates may be determined based on the highest values of the excess enthalpies with the API. Such solvent systems may be used directly for slurry crystallization of the stable form as well as for desolvation of the solvated forms by reslurry experiments to facilitate solvent-mediated transformation and conversion to a stable anhydrous non-solvated form .

\section{ACKNOWLEDGEMENTS}

The authors thank Dr. Frank Eckert for valuable discussions and suggestions.

\section{REFERENCES}

1. Aakeröy CB, Salmon DJ. 2005. Building co-crystals with molecular sense and supramolecular sensibility. CrystEngCommun 7:439-448.

2. Jones W, Motherwell WS, Trask AV. 2006. Pharmaceutical Co-crystals: An emerging approach to physical property enhancement. MRS Bulletin 31:875-879.

3. Schultheiss N, Newman A. 2009. Pharmaceutical co-crystals and their physicochemical properties. Cryst Growth Des 9:2950-2967.

4. Variankaval N, Wenslow R, Murry J, Hartman R, Helmy R, Kwong E, Clas S-D, Dalton C, Santos I. 2006. Preparation and solid-state characterization of nonstoichiometric co- 
crystals of a phosphodiesterase-IV inhibitor and l-tartaric acid. Cryst Growth Des 6:690700.

5. McNamara D, Childs S, Giordano J, Iarriccio A, Cassidy J, Shet M, Mannion R, O'Donnell E, Park A. 2006. Use of a glutaric acid co-crystal to improve oral bioavailability of a low solubility API. Pharm Res 23:1888-1897.

6. Trask AV. 2007. An overview of pharmaceutical co-crystals as intellectual property. Mol Pharm 4:301-309.

7. Vippagunta SR, Brittain HG, Grant DJ. 2001. Crystalline solids. Adv Drug Deliv Rev 48:3-26.

8. Trask AV, Motherwell WDS, Jones W. 2004. Solvent-drop grinding: Green polymorph control of co-crystallisation. Chem Commun 890-891.

9. Delori A, Friscic T, Jones W. 2012. The role of mechanochemistry and supramolecular design in the development of pharmaceutical materials. CrystEngComm 14:2350-2362.

10. Blagden N, Berry DJ, Parkin A, Javed H, Ibrahim A, Gavan PT, De Matos LL, Seaton CC. 2008. Current directions in co-crystal growth. New J. Chem. 32:1659-1672.

11. Basavoju S, Boström D, Velaga S. 2008. Indomethacin-saccharin co-crystal: Design, synthesis and preliminary pharmaceutical characterization. Pharm Res 25:530-541.

12. Zhang GG, Henry RF, Borchardt TB, Lou X. 2007. Efficient co-crystal screening using solution-mediated phase transformation. J Pharm Sci 96:990-995.

13. Issa N, Karamertzanis PG, Welch GWA, Price SL. 2009. Can the formation of pharmaceutical co-crystals be computationally predicted? I. Comparison of lattice energies. Cryst Growth Des. 9:442-453.

14. Karamertzanis PG, Kazantsev AV, Issa N, Welch GW, Adjiman CS, Pantelides CC, Price SL. 2009. Can the formation of pharmaceutical co-crystals be computationally predicted? 2. Crystal structure prediction. J Chem Theory Comput 5:1432-1448.

15. Cruz-Cabeza AJ, Day GM, Jones W. 2008. Towards prediction of stoichiometry in crystalline multicomponent complexes. Chem -Eur J 14:8830-8836.

16. Mohamed S, Tocher DA, Price SL. 2011. Computational prediction of salt and co-crystal structures-does a proton position matter? Int J Pharm 418:187-198.

17. Desiraju GR. 1995. Supramolecular synthons in crystal engineering - a new organic synthesis. Angew Chem Int Ed Engl 34:2311-2327.

18. Shattock TR, Arora KK, Vishweshwar P, Zaworotko MJ. 2008. Hierarchy of supramolecular synthons: Persistent carboxylic acid $\cdots$ pyridine hydrogen bonds in cocrystals that also contain a hydroxyl moiety. Cryst Growth Des 8:4533-4545.

19. Bis JA, Vishweshwar P, Weyna D, Zaworotko MJ. 2007. Hierarchy of supramolecular synthons: persistent hydroxyl-pyridine hydrogen bonds in co-crystals that contain a cyano acceptor. Mol Pharm 4:401-416.

20. Musumeci D, Hunter CA, Prohens R, Scuderi S, McCabe JF. 2011. Virtual co-crystal screening. Chem Sci 2:883-890.

21. Allen FH, Bellard S, Brice MD, Cartwright BA, Doubleday A, Higgs H, Hummelink T, Hummelink-Peters BG, Kennard O, Motherwell WDS, Rodgers JR, Watson DG. 1979. The cambridge crystallographic data centre: computer-based search, retrieval, analysis and display of information. Acta Crystallogr 35:2331-2339.

22. Fábián L. 2009. Cambridge structural database analysis of molecular complementarity in co-crystals. Cryst Growth Des 9:1436-1443. 
23. Babu NJ, Reddy LS, Nangia A. 2007. Amide-n-oxide heterosynthon and amide dimer homosynthon in cocrystals of carboxamide drugs and pyridine n-oxides. Mol Pharm 4:417-434.

24. Mohammad MA, Alhalaweh A, Velaga SP. 2011. Hansen solubility parameter as a tool to predict co-crystal formation. Int J Pharm 407:63 - 71.

25. Klamt A. 2011. The COSMO and COSMO-RS solvation models. Wiley interdisciplinary reviews: Computational molecular science 1:699-709.

26. Samas B, Seadeek C, Campeta AM, Chekal BP. 2011. A thermodynamic-based approach to analyzing a highly solvating polymorphic system: The desolvation window method. J Pharm Sci 100:186-194.

27. Klamt A. 2005. COSMO-RS: From Quantum Chemistry to Fluid Phase Thermodynamics and Drug Design, Elsevier Science Ltd., Amsterdam, The Netherlands.

28. (a) Eckert F, Klamt A. 2010. COSMOtherm, Version C2.1, Release 01.11; COSMOlogic GmbH \& Co. KG, Leverkusen, Germany. (b) Eckert F, Klamt A. 2002. Fast solvent screening via quantum chemistry: COSMO-RS approach. AIChE J 48:369-385.

29. TURBOMOLE, TURBOMOLE V6.3 2011, a development of University of Karlsruhe and Forschungszentrum Karlsruhe GmbH, 1989-2007, TURBOMOLE GmbH, since 2007; available from http://www.turbomole.com.

30. Becke AD. 1988. Density-functional exchange-energy approximation with correct asymptotic behavior. Phys Rev A 38:3098-3100.

31. (a) Perdew JP. 1986. Density-functional approximation for the correlation energy of the inhomogeneous electron gas. Phys Rev B 33:8822-8824. (b) Perdew JP. 1986. Erratum: density-functional approximation for the correlation energy of the inhomogeneous electron gas. Phys Rev B 34:7406-7406.

32. Schäfer A, Huber C, Ahlrichs R. 1994. Fully optimized contracted Gaussian basis sets of triple zeta valence quality for atoms Li to Kr. J Chem Phys 100:5829-5835.

33. Hornig M, Klamt A. 2005. COSMOfrag: A novel tool for high-throughput ADME property prediction and similarity screening based on quantum chemistry. J Chem Inf Model 45:1169-1177.

34. Klamt A, Eckert F, Diedenhofen M. 2009. Prediction of the free energy of hydration of a challenging set of pesticide-like compounds. J Phys Chem B 113:4508-4510.

35. OMEGA, OpenEye Scientific Software, Inc.: Santa Fe, NM.

36. Remenar JF, Morissette SL, Peterson ML, Moulton B, MacPhee JM, Guzmán HR, Almarsson Ö. 2003. Crystal engineering of novel co-crystals of a triazole drug with 1,4dicarboxylic acids. J Am Chem Soc 125:8456-8457.

37. Kojima T, Tsutsumi S, Yamamoto K, Ikeda Y, Moriwaki T. 2010. High-throughput cocrystal slurry screening by use of in situ Raman microscopy and multi-well plate. Int $\mathbf{J}$ Pharm 399:52 - 59.

38. Báthori NB, Lemmerer A, Venter GA, Bourne SA, Caira MR. 2011. pharmaceutical cocrystals with isonicotinamide - vitamin b3, clofibric acid, and diclofenac - and two isonicotinamide hydrates. Cryst Growth Des 11:75-87.

39. Berry DJ, Seaton CC, Clegg W, Harrington RW, Coles SJ, Horton PN, Hursthouse MB, Storey R, Jones W, Friščić T, Blagden N. 2008. Applying hot-stage microscopy to cocrystal screening: A study of nicotinamide with seven active pharmaceutical ingredients. Cryst Growth Des 8:1697-1712. 
40. Cheney ML, Weyna DR, Shan N, Hanna M, Wojtas L, Zaworotko MJ. 2010. Supramolecular architectures of meloxicam carboxylic acid co-crystals, a crystal engineering case study. Cryst Growth Des 10:4401-4413.

41. Seaton CC, Parkin A. 2011. Making benzamide co-crystals with benzoic acids: the influence of chemical structure. Cryst Growth Des 11:1502-1511.

42. Karki S, Friščić T, Fábián L, Laity PR, Day GM, Jones W. 2009. Improving mechanical properties of crystalline solids by co-crystal formation: new compressible forms of paracetamol. Advanced Materials 21:3905-3909.

43. Good DJ, Rodríguez-Hornedo N. 2009. Solubility advantage of pharmaceutical cocrystals. Cryst Growth Des 9:2252-2264.

44. Eckert F. 2006. Prediction of Solubility with COSMO-RS, in Developments and Applications in Solubility. Ed. Trevor Letcher, The Royal Society of Chemistry, UK.

45. Ben-Naim, A. 1987. Solvation Thermodynamics, Plenum Press, New York, NY.

46. http://www.fda.gov/Food/FoodIngredientsPackaging/default.htm

47. To generate a molecule library from the EAFUS data we have used the CAS numbers given there and retrieved corresponding SMILES strings from a novel NIH webservice called Chemical Identifier Resolver beta4 (available via $\mathrm{http}$ //cactus.nci.nih.gov/chemical/structure)._From the original EAFUS data all ionic constituents, polymeric constituents with undefined structure, constituents composed of several compounds have been removed resulting in a set of about 2000 compounds, which have subsequently been processed by COSMOfrag.

48. Buschmann HH. 2009. PCT int Appl. WO2010069561A1.

49. Oswald IDH, Allan DR, McGregor PA, Motherwell WDS, Parsons S, Pulham CR. 2002. The formation of paracetamol (acetaminophen) adducts with hydrogen-bond acceptors. Acta Crystallogr., Sect. B: Struct. Sci. 58:1057-1066.

50. Elbagerma MA, Edwards HGM, Munshi T, Scowen IJ. 2011. Identification of a new cocrystal of citric acid and paracetamol of pharmaceutical relevance. CrystEngComm 13:1877-1884.

51. Sander JR, Bučar D-K, Henry RF, Baltrusaitis J, Zhang GG, MacGillivray LR. 2010. A red zwitterionic co-crystal of acetaminophen and 2,4-pyridinedicarboxylic acid. J Pharm Sci 99:3676-3683.

52. Cheney ML, Weyna DR, Shan N, Hanna M, Wojtas L, Zaworotko MJ. 2011. Coformer selection in pharmaceutical co-crystal development: a case study of a meloxicam aspirin co-crystal that exhibits enhanced solubility and pharmacokinetics. J Pharm Sci 100:21722181.

53. Tumanov NA, Myz SA, Shakhtshneider TP, Boldyreva EV. 2012. Are meloxicam dimers really the structure-forming units in the 'meloxicam-carboxylic acid' co-crystals family? Relation between crystal structures and dissolution behaviour. CrystEngComm 14: 305313.

54. Luger P, Daneck K, Engel W, Trummlitz G, Wagner K. 1996. Structure and physicochemical properties of meloxicam, a new NSAID. Eur J Pharm Sci 4:175 - 187.

55. Campeta AM, Chekal BP, Abramov YA, Meenan PA, Henson MJ, Shi B, Singer RA, Horspool KR. 2010. Development of a targeted polymorph screening approach for a complex polymorphic and highly solvating API. J Pharm Sci 99:3874-3886.

56. Chekal BP, Campeta AM, Abramov YA, Feeder N, Glynn PP, McLaughlin RW, Meenan PA, Singer RA. 2009. The challenges of developing an API crystallization process for a 
complex polymorphic and highly solvating system. Part 1. Org Process Res Dev 13:13271337.

57. Nauha E, Saxell H, Nissinen M, Kolehmainen E, Schäfer A, Schlecker R. 2009. Polymorphism and versatile solvate formation of thiophanate-methyl. CrystEngComm, 11: 2536-2547..

58. Nauha E, Ojala A, Nissinen M, Saxell H. 2011. Comparison of the polymorphs and solvates of two analogous fungicides - a case study of the applicability of a supramolecular synthon approach in crystal engineering. CrystEngComm, 13: 49564964.

\section{Tables}

Table 1. Virtual coformer screening for itracanozole cocrystallization in 2:1 stoichiometry. ${ }^{36}$ Experimentally observed cocrystals are highlighted in green. Enthalpies $\mathrm{H}_{\mathrm{ex}}$ are calculated at the BP-TZVP-COSMO level of theory and are presented in $\mathrm{kcal} / \mathrm{mol}$.

\begin{tabular}{|l|l|}
\hline Coformer & $\mathbf{H}_{\mathbf{e x}}$ \\
\hline tartaric acid & -4.71 \\
\hline fumaric acid & -4.30 \\
\hline succinic acid & -2.85 \\
\hline malic acid & -2.72 \\
\hline glutaric acid & -2.71 \\
\hline malonic acid & -2.62 \\
\hline adipic acid & -2.59 \\
\hline maleic acid & -2.28 \\
\hline
\end{tabular}


Table 2. Summary of performance results of virtual coformer screenings.

\begin{tabular}{|l|l|l|l|}
\hline Compound & $\mathbf{A U C}$ & $\mathbf{E F}$ & $\mathbf{E F}_{\max }$ \\
\hline itracanozole $^{36}$ & 1.00 & 2 & 2 \\
\hline 3-cyanophenol $^{19}$ & 0.98 & 6.0 & 6.0 \\
\hline 4-cyanophenol $^{19}$ & 1.00 & 4.5 & 4.5 \\
\hline 3-cyanopyridine $^{19}$ & - & 6.0 & 18 \\
\hline 4-cyanopyridine $^{19}$ & 0.96 & 6.0 & 6.0 \\
\hline bicalutamide $^{19}$ & 0.94 & 4.5 & 9.0 \\
\hline nicotinamide $^{39}$ & 0.92 & 1.8 & 1.8 \\
\hline paracetamol $^{42}$ & 0.61 & 3.3 & 3.3 \\
\hline meloxicam $^{40}$ & 0.67 & 1.1 & 1.1 \\
\hline benzamide $^{41}$ & 0.71 & 0.9 & 1.9 \\
\hline indomethacin $^{24}$ & 0.49 & 5.3 & 5.3 \\
\hline indomethacin $^{37}$ & 0.54 & 1.3 & 9.0 \\
\hline
\end{tabular}


Table 3. Predictions of cocrystallization of isonicotinamide and nicotinamide with 4hydroxybenzoic acid, clofibric acid and diclofenac. Experimentally observed cocrystals are highlighted in green. ${ }^{38}$ Enthalpies $\mathrm{H}_{\mathrm{ex}}$ are calculated at the BP-TZVP-COSMO level of theory and are presented in $\mathrm{kcal} / \mathrm{mol}$. 1:1 stoichiometries were used in the calculations.

\begin{tabular}{|l|l|l|}
\hline Coformer & $\begin{array}{l}\mathbf{H}_{\text {ex, }} \\
\text { isonicotinamide }\end{array}$ & $\begin{array}{l}\mathbf{H}_{\text {ex, }} \\
\text { nicotinamide }\end{array}$ \\
\hline $\begin{array}{l}\text { 4-hydroxybenzoic } \\
\text { acid }\end{array}$ & -2.47 & -2.59 \\
\hline diclofenac & -1.97 & -2.05 \\
\hline clofibric acid & -1.69 & -1.77 \\
\hline
\end{tabular}


Table 4. Virtual solvent screening to avoid axitinib solvate crystallization and to facilitate desolvation of existing solid solvates. Experimentally observed solvents which do not form axitinib solvates are highlighted in green. ${ }^{55}$ Enthalpies $\mathrm{H}_{\mathrm{ex}}$ are calculated at the BP-TZVPCOSMO level of theory and are presented in $\mathrm{kcal} / \mathrm{mol}$. 1:1 stoichiometries were used in the calculations.

$\begin{array}{ll}\text { Solvent } & \mathbf{H}_{\mathrm{ex}} \\ \text { heptane } & 0.73 \\ \text { methylcyclohexane } & 0.67 \\ \text { 1-octanol } & 0.43 \\ \text { 1,2,3,4- } & \\ \quad \text { Tetrahydronaphthalene } & 0.4 \\ \text { nitromethane } & 0.39 \\ \text { p-Xylene } & 0.33 \\ \text { 1-pentanol } & 0.28 \\ \text { 3-Methyl-1-butanol } & 0.27 \\ \text { toluene } & 0.27 \\ \text { cyclohexanol } & 0.24 \\ \text { 1,2-dichlorobenzene } & 0.24 \\ \text { 1,2-dichloroethane } & 0.24 \\ \text { isobutanol } & 0.23 \\ \text { 1-butanol } & 0.23 \\ \text { ACN } & 0.21 \\ \text { 2-butanol } & 0.21 \\ \text { tert-butanol } & 0.2 \\ \text { IPA } & 0.17 \\ \text { trichloro-ethene } & 0.17 \\ \text { ethanol } & 0.13 \\ \text { methanol } & 0.08 \\ \text { methyl benzoate } & 0.03 \\ \text { allyl alcohol } & 0.03 \\ \text { water } & 0.01\end{array}$




$\begin{array}{ll}\text { benzyl alcohol } & -0.04 \\ \text { isoamyl acetate } & -0.05 \\ \text { DCM } & -0.06 \\ \text { n-butyl acetate } & -0.09 \\ \text { MIBK } & -0.14 \\ \text { tetramethylene sulfone } & -0.15 \\ \text { isopropyl acetate } & -0.16 \\ \text { methyl acetate } & -0.2 \\ \text { ethyl acetate } & -0.22 \\ \text { chloroform } & -0.26 \\ \text { 2-pentanone } & -0.28 \\ \text { MEK } & -0.32 \\ \text { dimethoxymethane } & -0.32 \\ \text { cyclohexanone } & -0.37 \\ \text { acetone } & -0.38 \\ \text { THF } & -0.61 \\ \text { pyridine } & -0.68 \\ \text { propionic acid } & -0.88 \\ \text { acetic acid } & -0.89 \\ \text { DMF } & -1.09 \\ \text { N-methylpyrrolidone } & \\ \text { (NMP) } & -1.34 \\ \text { DMSO } & -1.8\end{array}$


Table 5. Virtual solvent screening to avoid TM solvate crystallization. Experimentally observed solvents which do not form TM solvates are highlighted in green. ${ }^{57}$ Enthalpies $\mathrm{H}_{\mathrm{ex}}$ are calculated at the BP-TZVP-COSMO level of theory and are presented in $\mathrm{kcal} / \mathrm{mol}$. Experimental stoichiometries were used in the calculations whenever available, otherwise 1:1 mixtures were considered.

\begin{tabular}{lc} 
Solvent & $\mathbf{H}_{\mathbf{e x}}$ \\
water & 0.49 \\
toluene & 0.25 \\
1,2-DCB & 0.22 \\
benzene & 0.16 \\
ethanol & 0.12 \\
methanol & 0.10 \\
1,2-DCE & 0.07 \\
chloroform & 0.02 \\
DCM & -0.07 \\
acetonitrile & -0.36 \\
\hline cycloxehanone & -0.80 \\
acetone & -0.85 \\
dioxane & -1.16 \\
THF & -1.20 \\
pyridine & -1.35 \\
DMA & -2.29 \\
\hline DMSO & -2.84
\end{tabular}


Table 6. Virtual solvent screening to avoid TE solvate crystallization. Experimentally observed solvents which do not form TE solvates are highlighted in green. ${ }^{58}$ Enthalpies $\mathrm{H}_{\mathrm{ex}}$ are calculated at the BP-TZVP-COSMO level of theory and are presented in $\mathrm{kcal} / \mathrm{mol}$. Experimental stoichiometries were used in the calculations whenever available, otherwise 1:1 mixtures were considered.

\begin{tabular}{lc} 
Solvent & $\mathbf{H}_{\mathrm{ex}}$ \\
water & 0.50 \\
toluene & 0.12 \\
methanol & 0.10 \\
ethanol & 0.09 \\
1,2-DCE & 0.03 \\
chloroform & -0.08 \\
DCM & -0.11 \\
\hline acetonitrile & -0.27 \\
\hline acetone & -1.00 \\
dioxane & -1.15 \\
pyridine & -1.32 \\
DMSO & -2.73
\end{tabular}




\section{Figure Captions}

Figure 1. ROC curves of virtual coformer screenings based on $\mathrm{H}_{\mathrm{ex}}$ for a) 3-cyanophenol, ${ }^{19}$ b) 4cyanophenol, ${ }^{19}$ c) 4-cyanopyridine, ${ }^{19}$ d) bicalutamide, ${ }^{19}$ e) itracanazole,${ }^{36}$ f) nicotinamide, ${ }^{39}$ g) indomethacin, ${ }^{24} \mathrm{~h}$ ) indomethacin, ${ }^{37} \mathrm{k}$ ) benzamide, ${ }^{41} \mathrm{l}$ ) meloxicam,${ }^{40} \mathrm{~m}$ ) paracetamol. ${ }^{42}$ Enthalpies $\mathrm{H}_{\mathrm{ex}}$ are calculated at the BP-TZVP-COSMO level of theory.

Figure 2. COSMO-RS ranking of the carbamazepine solubility improvement by cocrystallization relative to the solubility of free drug. The experimental observation are taken from Good and Rodríguez-Hornedo. ${ }^{43}$ Here NCT- nicotinamide, MLN - malonic acid, GTAglutaric acid, OXA - oxalic acid, SAC - saccharin, SUC - succininc acid and SLC - salicylic acid. The calculations are performed at the BP-TZVP-COSMO level of theory.

Figure 3. Computational cocrystal screening of paracetamol and meloxicam against a subset of the EAFUS list. Compounds have been sorted according to their excess enthalpy $\mathrm{H}_{\mathrm{ex}}$. The straight line corresponds to a hypothetical random trial.

Figure 4. Molecular structures of a) axitinib, b) thiophanate-methyl (TM) and c) thiophanateethyl (TE), 


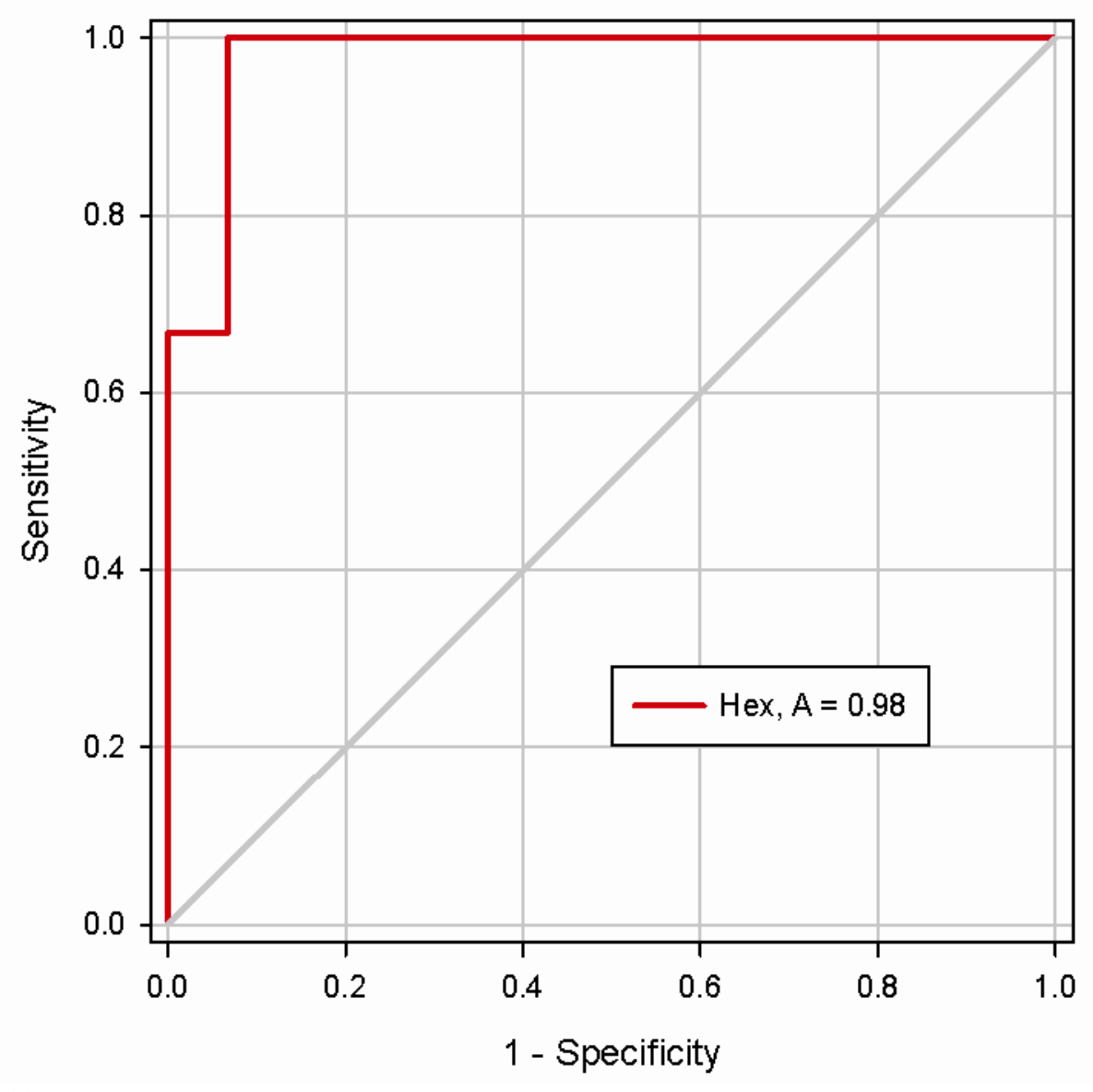

(a) 


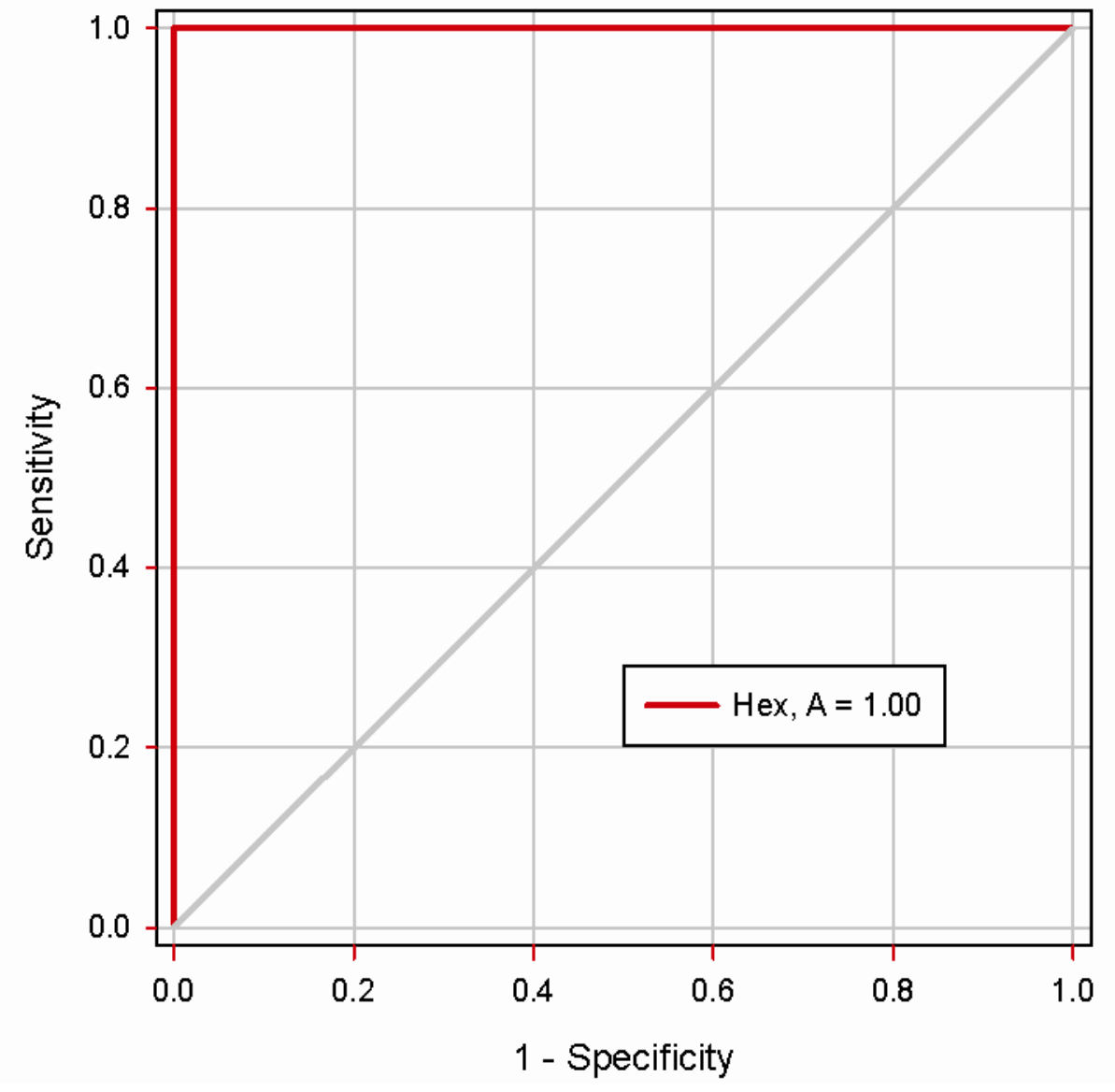

(b) 


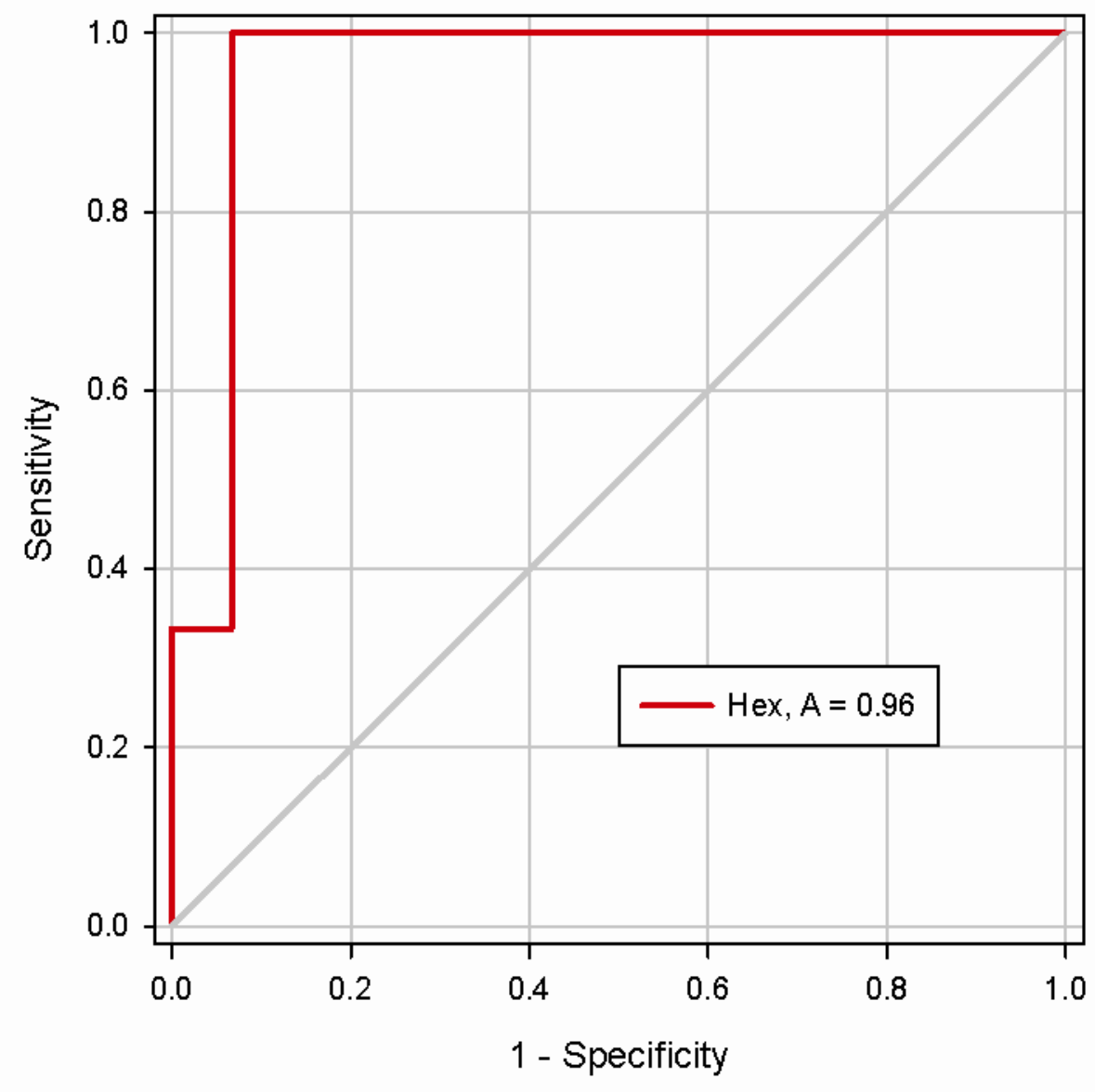

(c) 


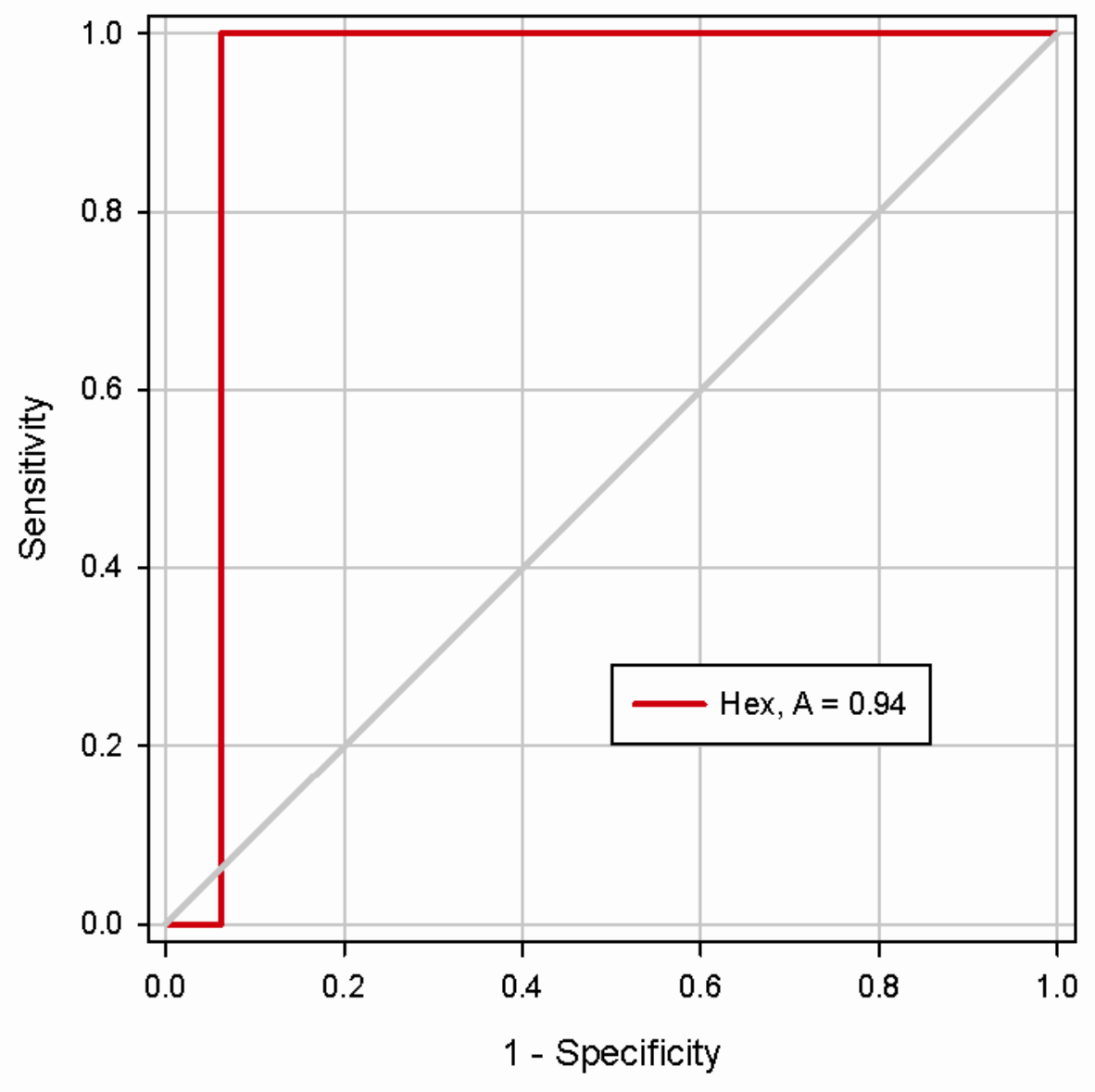

(d) 


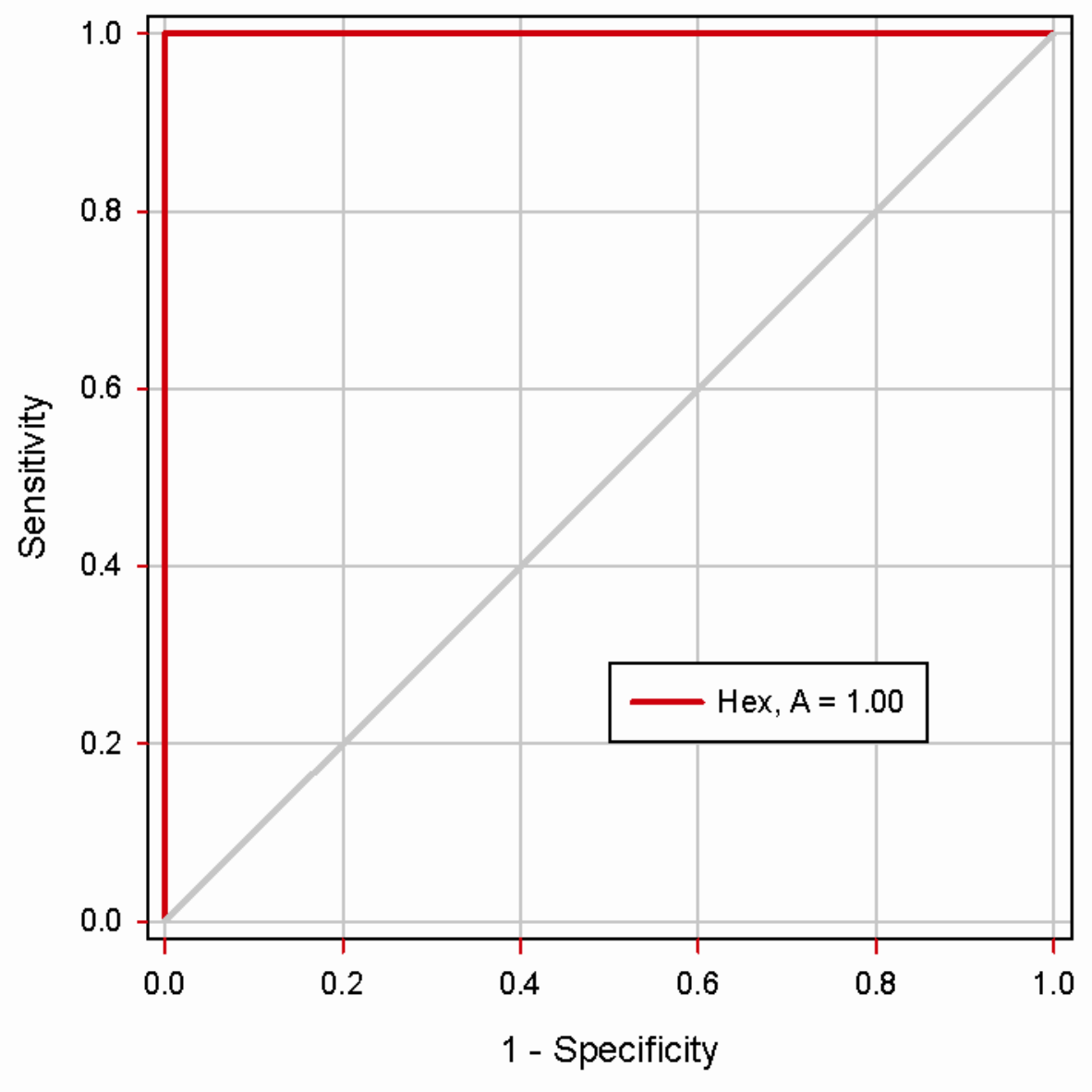

(f) 


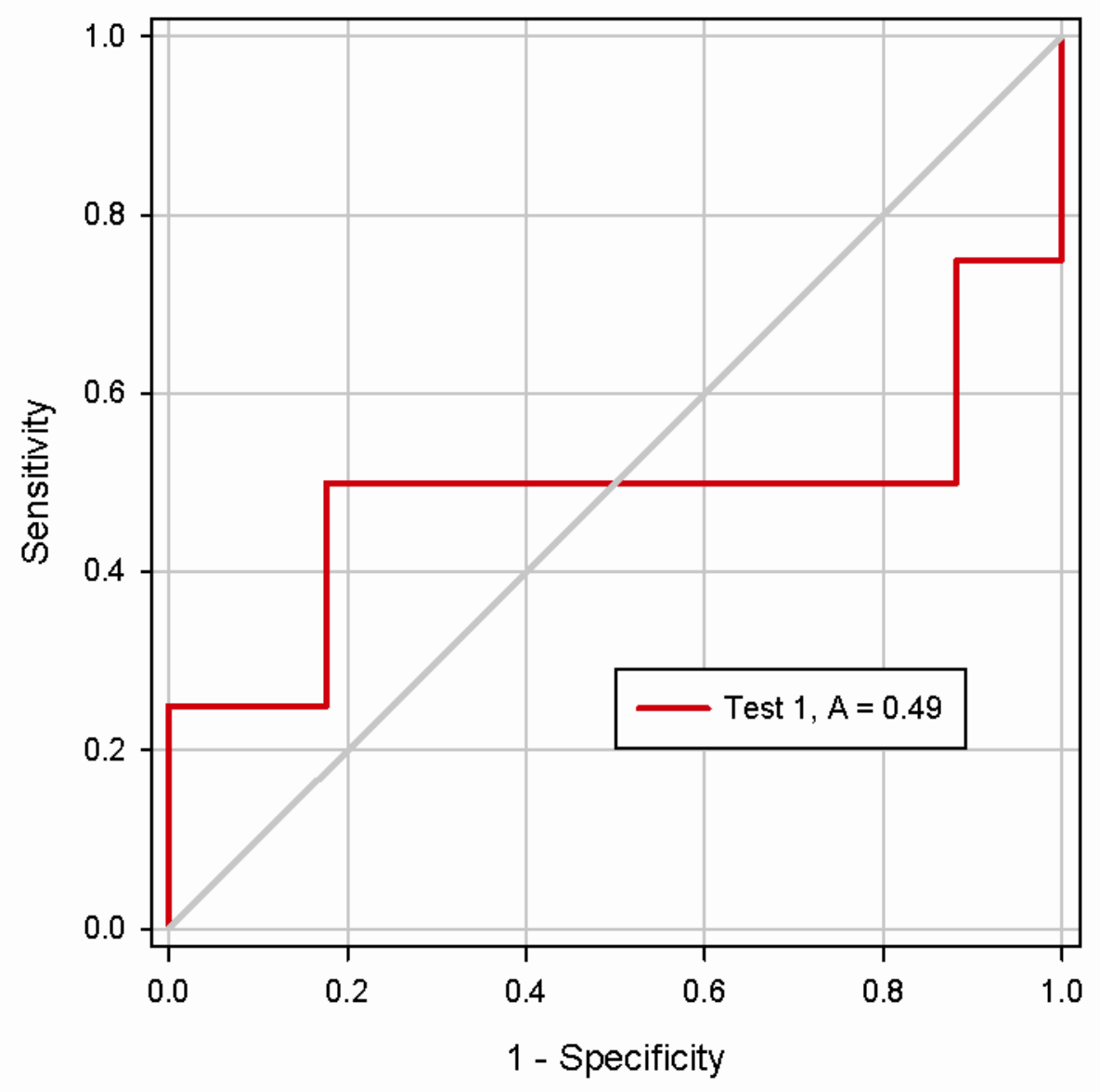

(g) 


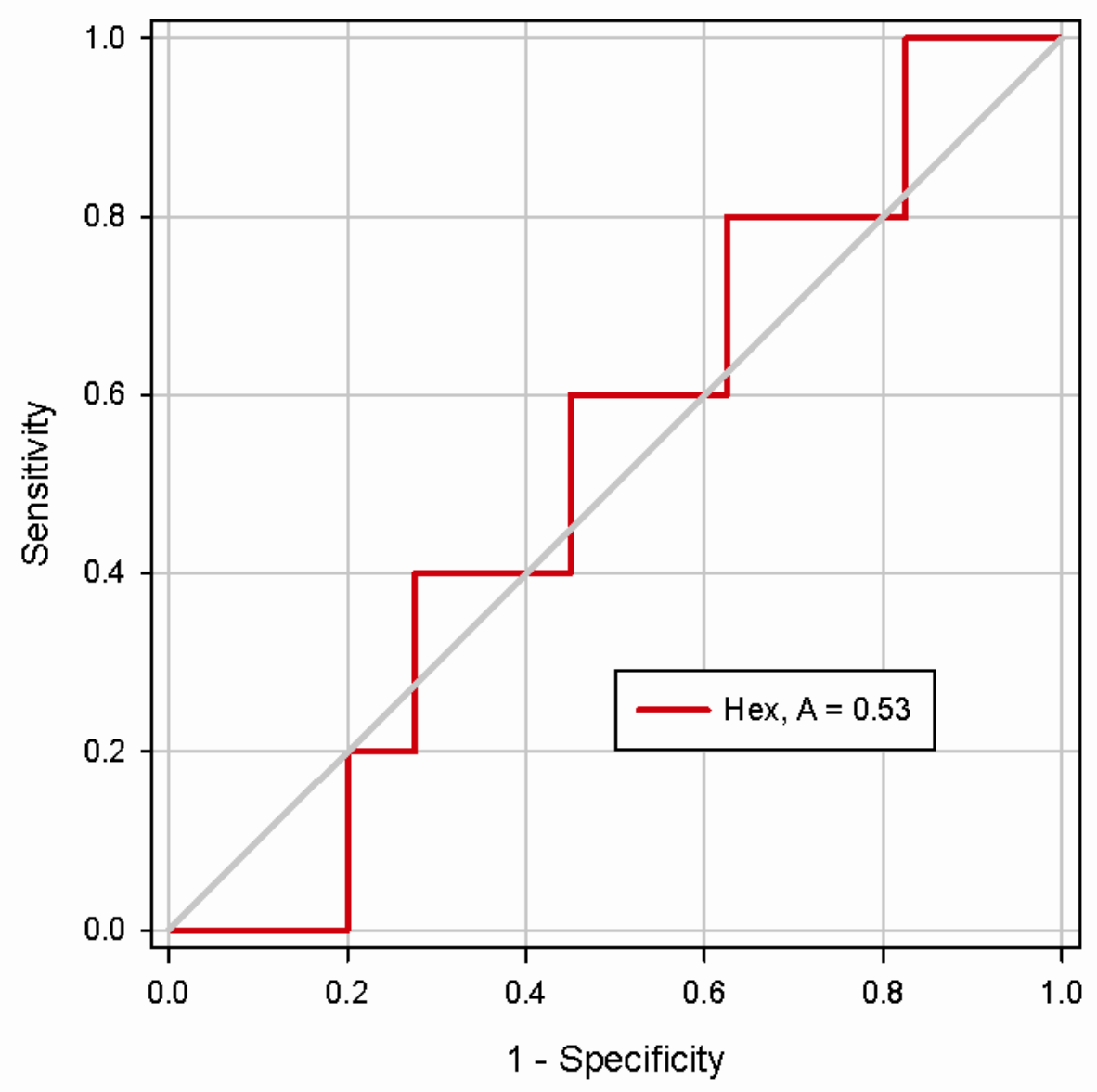

(h) 


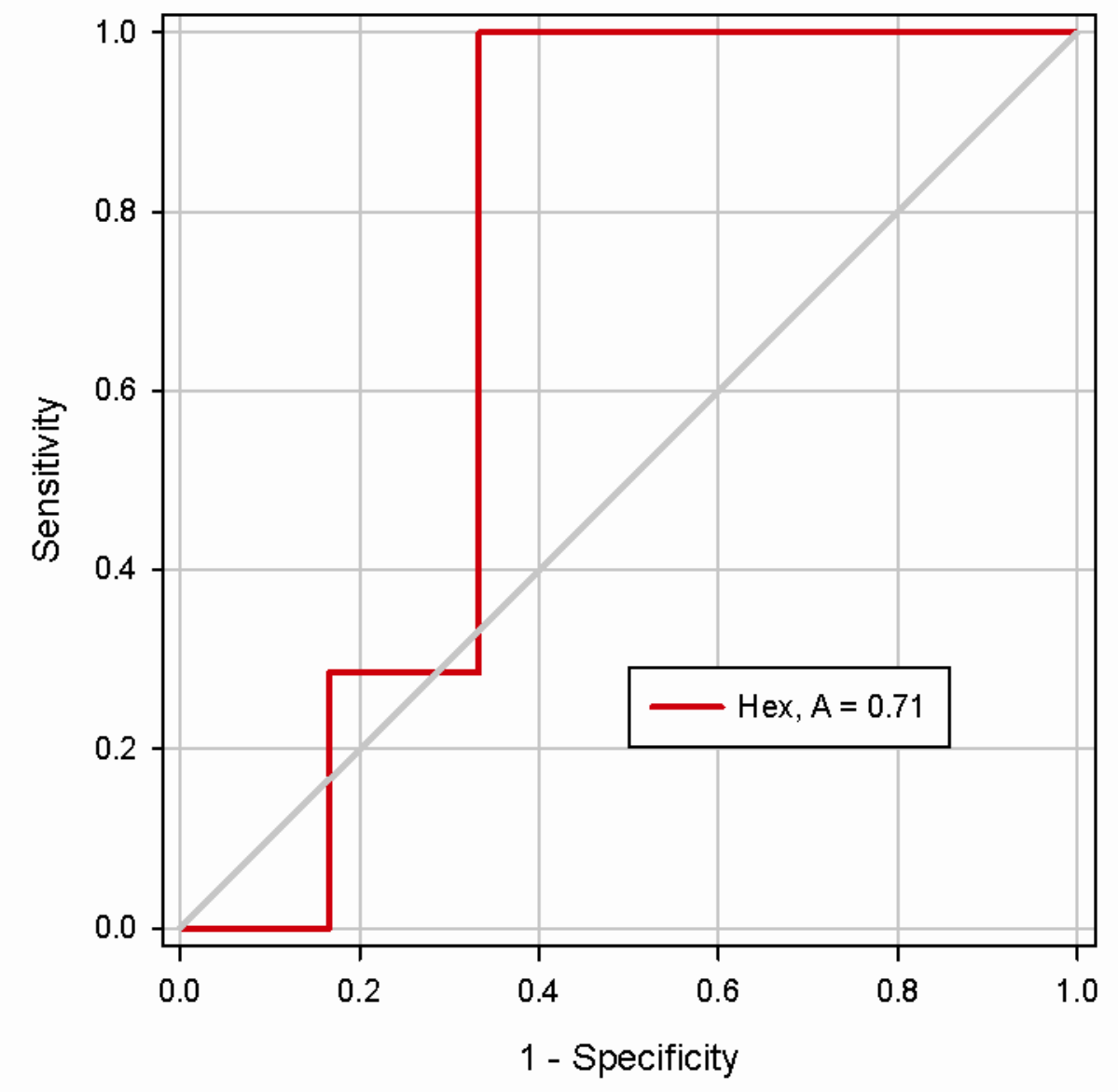

(k) 


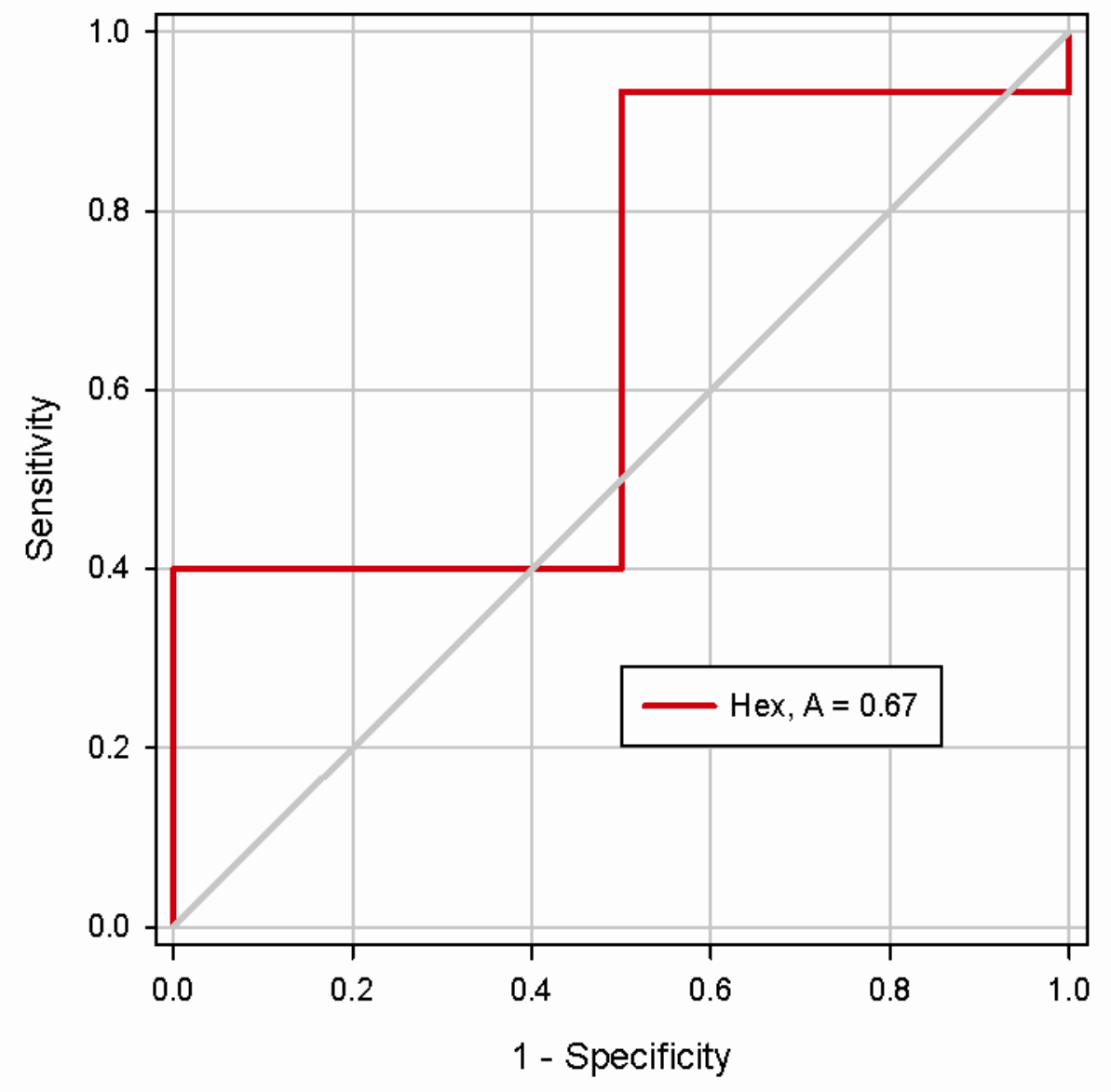

(1) 


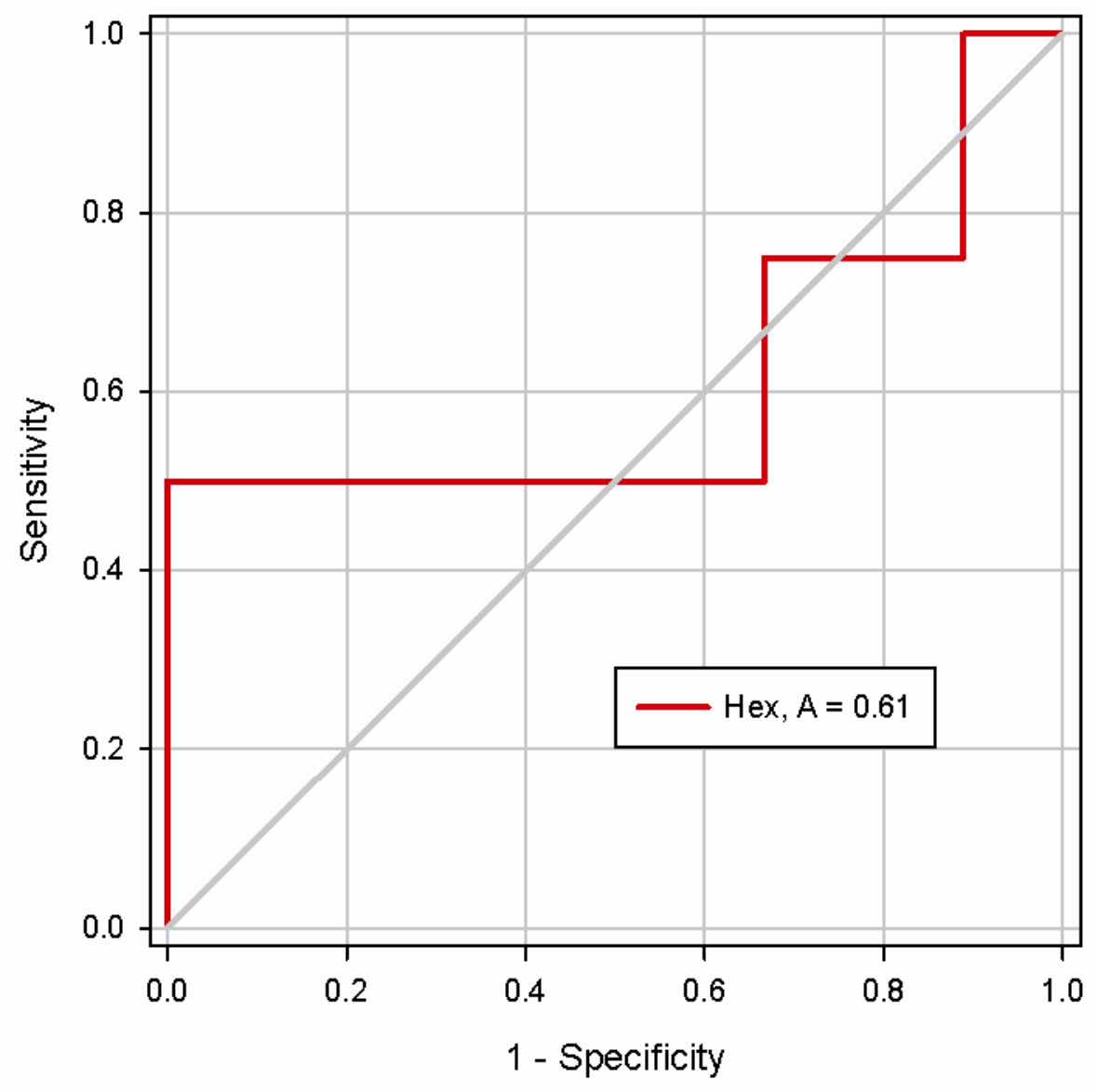

(m) 